\title{
Testosterone enhances estradiol's cardioprotection in ovariectomized rats
}

\author{
Aiying Liu*, Liping Gao*, Shoulei Kang, Ying Liu, Chuanying Xu, Hong Sun, Dongye Li ${ }^{1}$ and \\ Changdong Yan
}

Department of Physiology, Xuzhou Medical College, Xuzhou, Jiangsu 221002, China

${ }^{1}$ Institute of Cardiovascular Disease Research, Xuzhou Medical College Affiliated Hospital, Xuzhou 221002, China

(Correspondence should be addressed to H Sun; Email: sunh@xzmc.edu.cn)

*(A Liu and L Gao contributed equally to this work)

\begin{abstract}
After menopause, the development of cardiovascular disease (CVD) is due not only to estrogen decline but also to androgen decline. This study examined the effects of either estradiol $\left(\mathrm{E}_{2}\right)$ or testosterone replacement alone or $\mathrm{E}_{2}$-testosterone combination on isolated myocytes in ovariectomized (Ovx) rats subjected to ischemia/reperfusion (I/R). Furthermore, we determined whether the effects are associated with $\beta_{2}$-adrenoceptor $\left(\beta_{2}\right.$-AR). Five groups of adult female Sprague-Dawley rats were used: Sham operation (Sham) rats, bilateral Ovx rats, Ovx rats with $\mathrm{E}_{2} 40 \mu \mathrm{g} / \mathrm{kg}$ per day $(\mathrm{Ovx}+\mathrm{E})$, Ovx rats with testosterone $150 \mu \mathrm{g} / \mathrm{kg}$ per day $(\mathrm{Ovx}+\mathrm{T})$, and Ovx rats with $\mathrm{E}_{2} 40 \mu \mathrm{g} / \mathrm{kg}$ per day + testosterone $150 \mu \mathrm{g} / \mathrm{kg}$ per day $(\mathrm{Ovx}+\mathrm{E} / \mathrm{T})$. We determined the lactate dehydrogenase (LDH) release, percentage of rod-shaped cells and apoptosis of ventricular myocytes from rats of all groups subjected to I/R. Then, we determined the
\end{abstract}

above indices and contractile function with or without a selective $\beta_{2}$-AR antagonist ICI 118551 . We also determined the expression of $\beta_{2}-A R$. Our data show that either $E_{2}$ or testosterone replacement alone or $\mathrm{E}_{2}$ and testosterone in combination decreased the LDH release, increased the percentage of rod-shaped cells, reduced apoptotic cells (\%), and combination treatment appeared to be more effective than either $E_{2}$ or testosterone replacement alone. ICI 118551 abolished the effects of the three. Combination supplementation also enhanced the expression of $\beta_{2}-\mathrm{AR}$. We concluded that in Ovx rats, testosterone enhances $\mathrm{E}_{2}$ 's cardioprotection, while $\mathrm{E}_{2}$ and testosterone in combination was more effective and the protective effects may be associated with $\beta_{2}$-AR. The study highlights the potential therapeutic application for CVD in postmenopausal women.

Journal of Endocrinology (2012) 212, 61-69

\section{Introduction}

Epidemiological data showed that premenopausal women have a lower incidence of cardiovascular disease (CVD), compared with age-matched men. However, after menopause, the incidence of CVD rises sharply and remains the number one cause of death among women. Montalcini et al. (2007) found that the development of CVD after menopause is due not only to estrogen decline but also to androgen decline.

There is compelling evidence to suggest the role of estrogen in protecting the cardiomyocyte after ischemia/ reperfusion (I/R) injury. However, the cardioprotective role of estrogen was challenged by the findings of the Women's Health Initiative study (Rossouw et al. 2002), as well as a study published in the BMJ (Vickers et al. 2007). In these studies, estrogen replacement therapy increased cardiovascular events in postmenopausal women. As a result, the potential use of estrogen replacement was much reduced, and interest began to focus on the safety and efficacy of hormone therapy among postmenopausal women.

Recently, there is increasing interest in the use of testosterone as part of postmenopausal hormone therapy. Sievers et al. (2010) reported that low baseline testosterone in relatively older women is associated with increased all-cause mortality and cardiovascular events, which is largely independent of traditional risk factors. Low-dose testosterone supplementation improved functional capacity, insulin sensitivity and muscle strength in elderly female patients with chronic heart failure, and no androgenic side effects were detected (Iellamo et al. 2010). In several studies, addition of testosterone to estrogen therapy has been reported to improve sexual function and well-being in naturally and surgically menopausal women (Shifren et al. 2006). These findings prompted us to postulate that addition of physiological dose of testosterone to estrogen therapy may confer cardioprotection by direct action on the myocardium. 
Our previous study showed that estradiol $\left(\mathrm{E}_{2}\right)$ plays a cardioprotective role in female rat hearts subjected to $\mathrm{I} / \mathrm{R}$, and the effects are associated with increased expression of $\beta_{2}$-adrenoceptor $\left(\beta_{2}-\mathrm{AR}\right)$ (Wu et al. 2008). In addition, studies have demonstrated that testosterone at physiological levels increases the number of $\beta_{2}$-ARs (Xu et al. 1991), enhances the expression of $\alpha_{1 \mathrm{~A}^{-}}, \beta_{1^{-}}$, and $\beta_{2^{-}} \mathrm{AR}$ in rat hearts (Tsang et al. 2008, 2009). So, we speculated that $\beta_{2}$-AR may be a common downstream target of estrogen and testosterone that is involved in cardioprotection.

We hypothesized that $\mathrm{E}_{2}$ and testosterone $(\mathrm{E} / \mathrm{T})$ combination confers cardioprotection against $\mathrm{I} / \mathrm{R}$ injury and the action is associated with $\beta_{2}-\mathrm{AR}$. In this study, we evaluated the effect of $\mathrm{E} / \mathrm{T}$ combination on lactate dehydrogenase (LDH) release, percentage of rod-shaped cells, apoptosis, and contractile function. To further elucidate whether the effect was associated with the activation of $\beta_{2}-\mathrm{AR}$, we inhibited $\beta_{2^{-}}$ AR using a selective $\beta_{2}$-AR antagonist ICI 118 551, then, reassessed the above effects and ascertained the level of expression of $\beta_{2}-\mathrm{AR}$ using western blotting analysis.

\section{Materials and Methods}

\section{Experimental animals and materials}

These experiments were approved by the Animal Ethics Committee of the Medical College of Xuzhou. Seventy-dayold female Sprague-Dawley rats (Clean grade, Xuzhou Medical College, China) weighing 180-200 g were randomly divided into two groups. One group was Sham operated and received daily injections of vehicle and served as normal control (sham group). The other group underwent bilateral ovariectomy and was divided into four subgroups. Two weeks after being ovariectomized (Ovx), four subgroups of the Ovx rats received daily injections of 1) vehicle (Ovx group), 2) $\mathrm{E}_{2}$ (40 $\mu \mathrm{g} / \mathrm{kg}$, s.c., Sigma) (Ovx $+\mathrm{E}$ group), 3) testosterone $\left(150 \mu \mathrm{g} / \mathrm{kg}\right.$, s.c., Sigma) (Ovx $+\mathrm{T}$ group), and 4) $\mathrm{E}_{2}$ $(40 \mu \mathrm{g} / \mathrm{kg}$, s.c., Sigma $)+$ testosterone $(150 \mu \mathrm{g} / \mathrm{kg}$, s.c., Sigma) (Ovx $+\mathrm{E} / \mathrm{T}$ group) for 4 weeks according to previous studies (Tsang et al. 2008, Wu et al. 2008). All surgical procedures were performed under anesthesia with sodium pentobarbitone $(60 \mathrm{mg} / \mathrm{kg}$ body weight, i.p.), chloral hydrate (300 mg/kg body weight, i.p.), and ketamine $(20 \mathrm{mg} / \mathrm{kg}$ body weight, i.p.). The adequacy of anesthesia was monitored by observing limb withdrawal and palpebral reflexes.

\section{Experimental protocol}

Ventricular myocytes were isolated from the hearts of all rats, and cultured in Dulbecco's minimal essential medium at a density of $2 \times 10^{4}$ cells/well on 12 -well culture dishes. The culture dishes were not coated in any way. The cells in medium were incubated at cell culture chamber with $37^{\circ} \mathrm{C}$, $100 \%$ humidity and $5 \% \mathrm{CO}_{2}$. The myocytes of Sham group did not experience the treatment of $\mathrm{I} / \mathrm{R}$. The myocytes of other groups were cultured for $6 \mathrm{~h}$, and then subjected to $3 \mathrm{~h}$ ischemia followed by $4 \mathrm{~h}$ reperfusion. During the entire simulated ischemic period, the cell medium was replaced with an 'ischemic buffer' that contained (mM) $118 \mathrm{NaCl}, 24$ $\mathrm{NaHCO}_{3}, 1 \cdot 0 \mathrm{NaH}_{2} \mathrm{PO}_{4}, 2 \cdot 5 \mathrm{CaCl}_{2}-2 \mathrm{H}_{2} \mathrm{O}, 20$ sodium lactate, $16 \mathrm{KCl}$, and 102 -deoxyglucose (pH adjusted to 6.2) as reported previously (Das \& Sarkar 2006), and the cells were incubated at $37^{\circ} \mathrm{C}$ in tri-gas incubator equilibrated with $94 \% \mathrm{~N}_{2}+1 \% \mathrm{O}_{2}$ $+5 \% \mathrm{CO}_{2}$ for $3 \mathrm{~h}$. Reperfusion was accomplished by replacing the ischemic buffer with normal cell medium and myocytes were incubated at cell culture chamber with $37^{\circ} \mathrm{C} 100 \%$ humidity and $5 \% \mathrm{CO}_{2}$ for $4 \mathrm{~h}$. In addition, the cells in Ovx, $\mathrm{Ovx}+\mathrm{E}, \mathrm{Ovx}+\mathrm{T}$, and $\mathrm{Ovx}+\mathrm{E} / \mathrm{T}$ groups were incubated $1 \mathrm{~h}$ with or without a selective $\beta_{2}$-AR antagonist ICI 118551 (Sigma) and then were subjected to $\mathrm{I} / \mathrm{R}$. The $\mathrm{LDH}$ release, percentage of rod-shaped cells, apoptosis, and contractile function were assessed at the end of reperfusion.

\section{Isolation of ventricular myocytes}

The rats were heparinized, anesthetized with sodium pentobarbitone $(60 \mathrm{mg} / \mathrm{kg}$ body weight, i.p.) and ketamine (20 mg/kg body weight, i.p.), and then humanely killed by cervical dislocation. Ventricular myocytes were isolated, using the collagenase perfusion method described previously (Sun et al. 2006, Wu et al. 2008, Hao et al. 2009). There was no statistically significant difference in the viability of freshly prepared myocytes from all the groups, which ensures that percentage survival is equivalent among individual preparations/plates. After isolation, they were allowed to stabilize for at least $30 \mathrm{~min}$ before experiments.

Table 1 General features of experimental animals $(n=10$ per group). Data shown are mean \pm S.E.M.

\begin{tabular}{|c|c|c|c|c|c|}
\hline & Sham & Ovx & Ovx $+E$ & $\mathbf{O v x}+\mathbf{T}$ & $\mathbf{O v x}+\mathrm{E} / \mathrm{T}$ \\
\hline Body weight (g) & $248 \pm 7$ & $350 \pm 10^{\#}$ & $271 \pm 7^{*}$ & $336 \pm 7^{\# \$}$ & $249 \pm 4^{*+}$ \\
\hline Heart weight (g) & $0.92 \pm 0 \cdot 02$ & $1 \cdot 04 \pm 0 \cdot 04$ & $1 \cdot 01 \pm 0 \cdot 03$ & $1 \cdot 04 \pm 0.03$ & $0.93 \pm 0.03$ \\
\hline Heart weight/body weight ratio $(\mathrm{mg} / \mathrm{g})$ & $3 \cdot 70 \pm 0 \cdot 05$ & $3 \cdot 00 \pm 0 \cdot 05^{\#}$ & $3 \cdot 60 \pm 0 \cdot 06^{*}$ & $3 \cdot 10 \pm 0 \cdot 04^{\# \$}$ & $3 \cdot 70 \pm 0 \cdot 05^{*+}$ \\
\hline Serum $E_{2}(p g / m l)$ & $66 \pm 9$ & $13 \pm 2^{\#}$ & $62 \pm 8^{*}$ & $13 \pm 3^{\# \# \$ \$}$ & $63 \pm 10^{*++}$ \\
\hline Serum testosterone $(\mathrm{ng} / \mathrm{ml})$ & $1 \cdot 65 \pm 0.07$ & $1 \cdot 12 \pm 0 \cdot 04^{\#}$ & $0 \cdot 79 \pm 0 \cdot 04^{\# * * *}$ & $1 \cdot 56 \pm 0 \cdot 10^{* * \$}$ & $1 \cdot 48 \pm 0 \cdot 11^{* * * \$}$ \\
\hline
\end{tabular}

${ }^{\sharp} P<0.001$ and ${ }^{\# \#} P<0.01$ vs Sham, ${ }^{*} P<0.001,{ }^{* *} P<0.01$, and ${ }^{* * *} P<0.05$ vs Ovx, ${ }^{\$} P<0.001$ and ${ }^{\$ \$} P<0.01$ vs Ovx $+E,{ }^{+} P<0 \cdot 001$ and ${ }^{++} P<0 \cdot 01$ vs Ovx $+\mathrm{T}$. 


\section{Measurement of plasma $E_{2}$ and testosterone concentrations}

Immediately after the heart was removed, $2 \cdot 5 \mathrm{ml}$ of blood was drawn from the thorax and put into a tube containing $0.6 \mathrm{ml}$ of $5 \%$ sodium citrate. Sera were separated by centrifugation and stored at $-80{ }^{\circ} \mathrm{C}$ until assayed. The $\mathrm{E}_{2}$ and testosterone concentrations were measured by a chemiluminescent enzyme immunoassay (Access, Beckman, Fullerton, CA, USA), according to the manufacturer's instructions. Sensitivity for the testosterone determination was $0.05 \mathrm{ng} / \mathrm{ml}$ and for $E_{2}$ was $10 \mathrm{pg} / \mathrm{ml}$. Intra-assay variance for testosterone and $\mathrm{E}_{2}$ was $6 \cdot 3$ and $5 \cdot 5 \%$ respectively.

\section{Measurement of $\mathrm{LDH}$ release in culture medium}

The release of LDH in culture medium was determined after $\mathrm{I} / \mathrm{R}$ as an indication of myocardial injury. The concentration of LDH was assayed spectrophotoelectrically as described previously (Lucchinetti et al. 2008). The sensitivity and intraassay variance for $\mathrm{LDH}$ was $0 \cdot 001 \mathrm{U} / 1$ and $2 \%$ respectively. All samples were assayed in triplicate.

\section{Identification of rod-shaped cells}

Rod-shaped cells are the viable cells and round-shaped cells are nonviable cells. Five micrographs were taken randomly per sample with an inverted microscope. All rod- and roundshaped myocytes in these fields were measured. In total, 600800 cells were measured for one condition of one preparation. The percentage of rod cells in total cells was calculated with Image-Pro Express Software (Media Cybernetics, Glen Burnie, $\mathrm{MD}$, USA). The sensitivity and intra-assay variance for percentage of rod-shaped cells was $0 \cdot 01$ and $2 \%$ respectively. The analysis of myocytes was done under blind conditions.

\section{Measurement of cardiac myocyte contraction}

Contractile function was monitored by a video edge detector system as described previously (Wu et al. 2008). Briefly, a few drops of medium containing ventricular myocytes were added to an open chamber on the stage of an inverted microscope (Olympus, Tokyo, Japan). Five minutes later, myocytes spontaneously attached to the bottom of the chamber, which was filled with Krebs-Henseleit buffer (KHB) and $100 \mathrm{nM}$ isoprenaline to mimic the in vivo situation when there is sympathetic activity. $\mathrm{KHB}(2 \mathrm{ml} / \mathrm{min}$, containing $2.0 \mathrm{mM}$ $\mathrm{Ca}^{2+}$ ) was adjusted to $\mathrm{pH} 7 \cdot 4$ by equilibration with $95 \%$ $\mathrm{O}_{2}-5 \% \mathrm{CO}_{2}$. The ventricular myocytes were paced with electrical field stimulation $(0 \cdot 5 \mathrm{~Hz})$. The myocytes used were rod-shaped with clear sarcomeres. At least ten myocytes per experimental group per heart were studied. The outputs of the video edge detector were sent to a computer. Contractile function was assessed using the following indices: shortening amplitude, time-to-peak (TTP) contraction and time-to$100 \%$ relaxation $\left(\mathrm{R}_{100}\right)$. The sensitivity for the shortening amplitude, TTP, and $\mathrm{R}_{100}$ was $0 \cdot 1 \%, 0 \cdot 01$ and $0 \cdot 01 \mathrm{~ms}$ respectively. Intra-assay variance for shortening amplitude, TTP, and $\mathrm{R}_{100}$ was less than $\sim 5 \%$ for all.

\section{Hoechst 33258 DNA staining}

Nuclear staining with Hoechst 33258 was assessed to detect chromatin condensation or nuclear fragmentation, which is characteristic of apoptosis. Each of the group cells was cultured on sterile cover glasses placed in the six-well plates and fixed with 4\% paraformaldehyde and stained with $1 \mu \mathrm{g} / \mathrm{ml}$ Hoechst 33258 (Sigma) for $10 \mathrm{~min}$ at room temperature in the dark. The cells were then washed three times with sterilized, distilled $\mathrm{H}_{2} \mathrm{O}$. Cells were counted and 200 were isolated and scored for the incidence of apoptotic chromatin changes using a fluorescence microscope (Olympus). The sensitivity and intra-assay variance for apoptotic cells was $0 \cdot 01$ and $2 \%$ respectively.
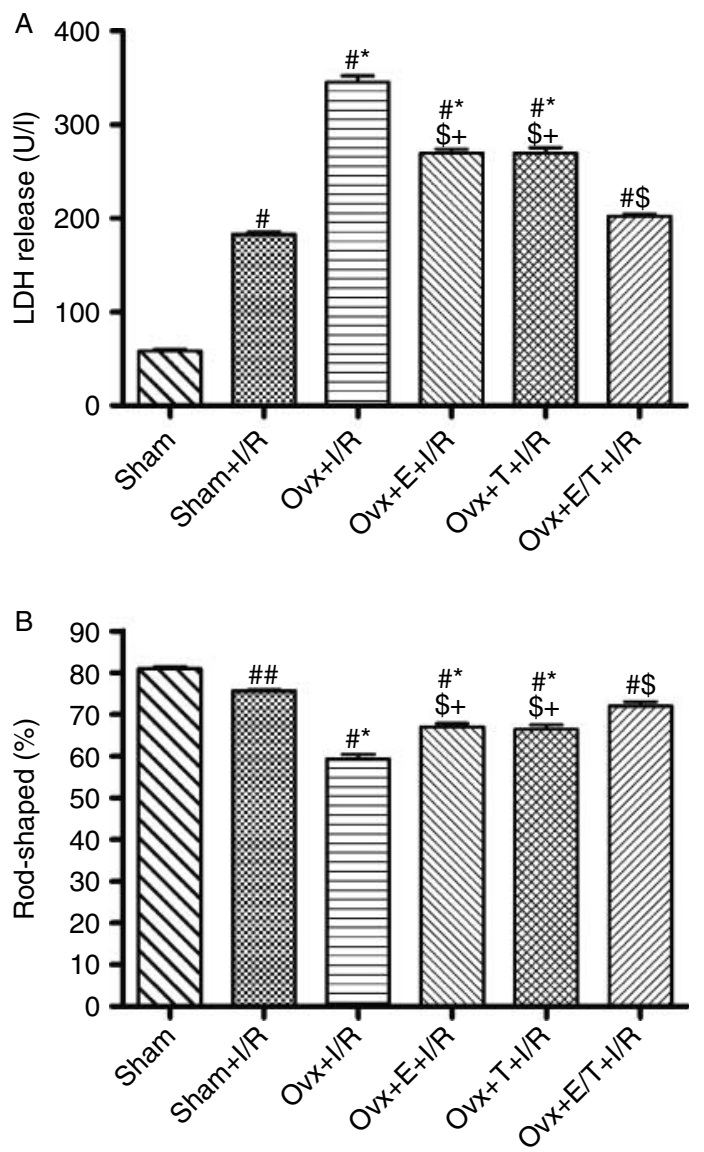

Figure $1 \mathrm{E} / \mathrm{T}$ combination reduced injury and increased viability. (A) $\mathrm{LDH}$ release. (B) Percentage of rod-shaped cells. Ventricular myocytes were subjected to I/R. Data shown are mean \pm S.E.M. $n=8$ hearts in each group. ${ }^{\sharp} P<0 \cdot 001$ and ${ }^{\# \#} P<0 \cdot 01$ vs Sham, $* P<0 \cdot 001$ vs Sham $+\mathrm{I} / \mathrm{R},{ }^{\$} P<0.001$ vs Ovx $+\mathrm{I} / \mathrm{R}$, and ${ }^{+} P<0.001$ vs Ovx + $\mathrm{E} / \mathrm{T}+\mathrm{I} / \mathrm{R}$. 


\section{Western blot analysis}

After I/R, ventricular myocytes were collected from each group and membrane protein from myocytes was extracted as described previously (Wu et al. 2008). In brief, ventricular myocytes were homogenized followed by centrifugation at $6660 \mathrm{~g}$ for $15 \mathrm{~min}$ at $4{ }^{\circ} \mathrm{C}$. The pellet was dispersed in $400 \mu \mathrm{l}$ of the original buffer. Protein concentration was determined with BCA Protein Assay kit (Beyotime Biotechnology, Haimen, China). The protein sample $(60 \mu \mathrm{g})$ was separated by $10 \%$ SDS-PAGE, and then transferred onto nitrocellulose membranes, blocked and probed with polyclonal antibodies (1:200, Santa Cruz Biotechnology, Santa Cruz, CA, USA) for the $\beta_{2}$-ARs. An alkaline phosphatase-linked anti-rabbit $\operatorname{IgG}(1: 1000$ dilution) was used as secondary antibody. Protein bands were shown by nitro blue tetrazolium and 5-bromo-4chloro-3-indolyl-phosphate. The membranes were scanned into the computer, and relative intensity of bands was analyzed by Image J 3.0 system (NIH, Bethesda, MD, USA).

\section{Statistical analysis}

In each experimental series, data are presented as mean \pm s.E.M. Statistical analysis was performed with GraphPad Prism 4.0 (San Diego, CA, USA). Statistical significance $(P<0 \cdot 05)$ for each variable was estimated by one-way ANOVA followed by Bonferroni post-hoc tests.

\section{Results}

\section{General features of experimental animals}

Six weeks after Ovx, the female rats exhibited significant reductions in serum $\mathrm{E}_{2}(P<0 \cdot 001)$ and total testosterone $(P<0 \cdot 001)$ level accompanied by a significant increase in body weight $(P<0 \cdot 001)$ and a significant reduction in heart weight/body weight ratio $(P<0 \cdot 001), \mathrm{E} / \mathrm{T}$ combination reversed the effects. Compared with Ovx group, $E_{2}$ replacement alone significantly reduced body weight $(P<0 \cdot 001)$, increased heart weight/body weight ratio $(P<0 \cdot 001)$ and the serum $\mathrm{E}_{2}$ level $(P<0 \cdot 001)$, but further decreased the total serum testosterone level $(P<0 \cdot 05)$; testosterone replacement alone markedly increased serum total testosterone level $(P<0 \cdot 01)$, whereas it had no significant effect on body weight, heart weight/body weight ratio and serum $E_{2}$ level (Table 1).

\section{E/T combination reduced injury and increased viability}

Cell injury was monitored after I/R by assaying LDH release in the culture medium. Rod-shaped cells are the viable cells and the percentage of rod-shaped cells is representative of the viability of ventricular myocytes. The baseline level of $\mathrm{LDH}$ release was the same in any of the Ovx groups. I/R induced a marked increase in the release of LDH (Fig. 1A) and reduction in percentage of rod-shaped cells (Fig. 1B).
The LDH release was further elevated (Fig. $1 \mathrm{~A} ; P<0 \cdot 001$ ) and percentage of rod-shaped cells (Fig. 1B; $P<0.001$ ) was further declined, in $\mathrm{Ovx}+\mathrm{I} / \mathrm{R}$ group than $\mathrm{Sham}+\mathrm{I} / \mathrm{R}$ group. $\mathrm{E} / \mathrm{T}$ combination replacement restored the values to those of the Sham $+\mathrm{I} / \mathrm{R}$ group (Fig. $1 \mathrm{~A}$ and $\mathrm{B}$ ). Both $\mathrm{E}_{2}$ and testosterone replacement alone reduced the $\mathrm{LDH}$ release (Fig. 1A; $P<0.001$ vs $\mathrm{Ovx}+\mathrm{I} / \mathrm{R}$ ) and enhanced percentage of rod-shaped cells (Fig. 1B; $P<0.001$ vs Ovx + I/R), but did not restore the values to those of the Sham + I/R group.

\section{E/T combination reduced apoptotic cells (\%)}

After Hoechst 33258 staining, apoptotic cell nuclei appeared either shrunken and irregularly shaped or degraded with aggregation and fragmentation of chromatin; normal nuclei have blue chromatin with organized structure (Fig. 2A). I/R markedly increased the apoptotic cells (\%; Fig. 2B), but the $\mathrm{Ovx}+\mathrm{I} / \mathrm{R}$ group had the highest
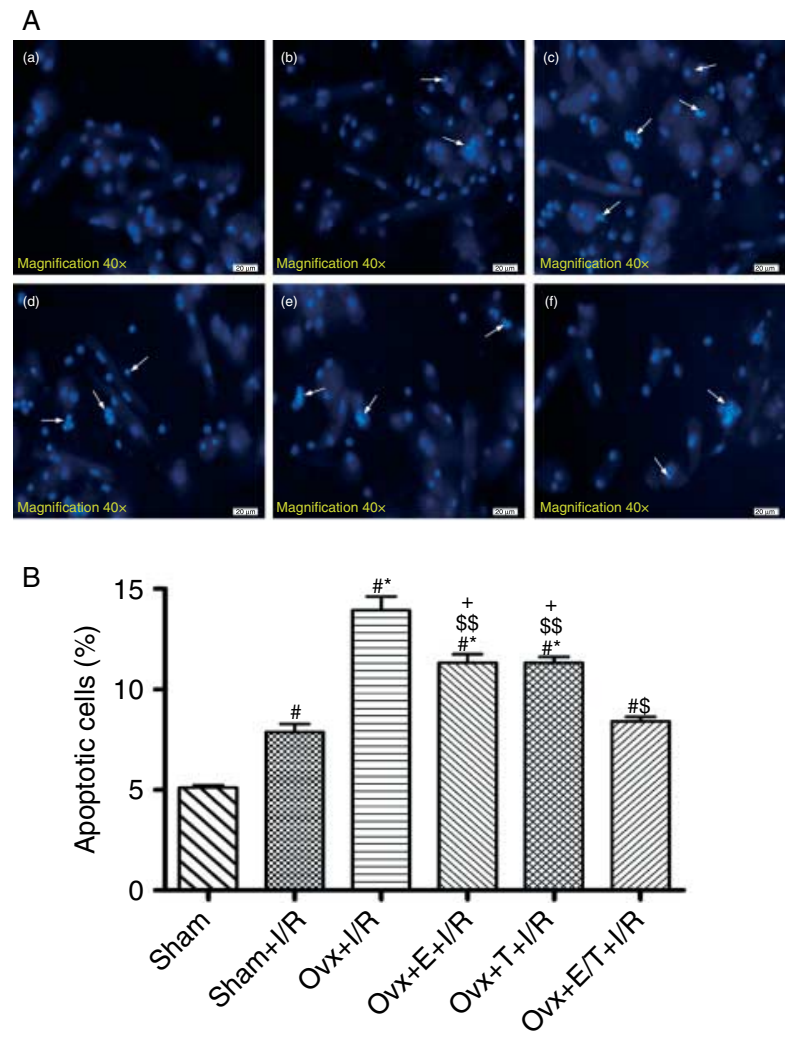

Figure $2 \mathrm{E} / \mathrm{T}$ combination inhibited apoptosis. (A) Fluorescence images of Hoechst 33258-stained. The bright parts (arrows) were the aggregation and fragmentation of chromatin. The shrunken and irregularly shaped nuclei indicate apoptosed cells. a, Sham group; b, Sham + I/R group; $c, O v x+I / R ; d, O v x+E+I / R ; e, O v x+T+I / R$; and $f, O v x+E / T+I / R$ (original magnification $\times 100$ ). (B) Apoptotic cells $(\%)$. Ventricular myocytes were subjected to I/R. Data shown are mean \pm S.E.M. $n=8$ hearts in each group. ${ }^{\sharp} P<0 \cdot 001$ vs Sham, ${ }^{*} P<0.001$ vs Sham $+\mathrm{I} / \mathrm{R},{ }^{\$} P<0.001$ and ${ }^{\$} P<0.01$ vs $\mathrm{Ovx}+\mathrm{I} / \mathrm{R}$, and ${ }^{+} P<0 \cdot 001$ vs Ovx $+E / T+\mathrm{I} / \mathrm{R}$. 
apoptotic cells (\%; Fig. 2A and B). E/T combination returned to that of the Sham $+\mathrm{I} / \mathrm{R}$ group (Fig. $2 \mathrm{~A}$ and $\mathrm{B}$ ). The apoptotic cells (\%) were decreased in Ovx $+\mathrm{E}+\mathrm{I} / \mathrm{R}$ and $\mathrm{Ovx}+\mathrm{T}+\mathrm{I} / \mathrm{R}$ groups, compared with $\mathrm{Ovx}+\mathrm{I} / \mathrm{R}$ group (Fig. 2B; $P<0.01$ ), but it is higher than the $\mathrm{Ovx}+\mathrm{E} / \mathrm{T}+\mathrm{I} / \mathrm{R}$ group (Fig. 2B; $P<0 \cdot 001$ ).

\section{ICI $118551(55 \mathrm{nM})$ abolished the effects of hormone replacement on injury and viability}

To determine the roles of crosstalk between $\beta_{2}$-ARs and combination supplementation, a selective $\beta_{2}$-AR antagonist ICI $118551(55 \mathrm{nM})$ was administered to ventricular myocytes, which had been isolated from Ovx, Ovx $+\mathrm{E}$, $\mathrm{Ovx}+\mathrm{T}$, and $\mathrm{Ovx}+\mathrm{E} / \mathrm{T}$ rats, and subjected to I/R. Ovx markedly increased the release of $\mathrm{LDH}$, declined the percentage of rod-shaped cells and increased the percentage of apoptotic cells. The effects were reversed by E/T combination, $\beta_{2}$-AR antagonist ICI 118551 abolished the reversed effects of $\mathrm{E} / \mathrm{T}$ combination. Both $\mathrm{E}_{2}$ and testosterone replacement alone reduced the LDH release, enhanced percentage of rod-shaped cells and decreased the percentage of apoptotic cells, and $\beta_{2}$-AR antagonist ICI 118551 also abolished the effects. However, in ventricular myocytes from Ovx rats, there was no significant difference in LDH release, percentage of rod-shaped and apoptotic cells (\%) with or without $\beta_{2}$-AR antagonist ICI 118551 (Fig. 3).

\section{$E / T$ combination improved contractile function of isolated ventricular myocytes subjected to I/R and ICI $118551(55 \mathrm{nM})$ abolished the effects}

Ovx markedly increased shortening amplitude, prolonged TTP contraction and shortened $R_{100}$. Inhibition of $\beta_{2}$ AR with ICI 118551 did not change the effects in Ovx rats. However, combination supplementation decreased shortening amplitude, shortened TTP, prolonged $\mathrm{R}_{100}$ to the levels of Sham group. Inhibition of $\beta_{2}$-AR with ICI 118551 abolished the effects in the $\mathrm{Ovx}+\mathrm{E} / \mathrm{T}$ group. $\mathrm{E}_{2}$ replacement alone reduced shortening amplitude, but had no significant effect on TTP and $\mathrm{R}_{100}$. However, testosterone replacement alone had no significant effect on shortening amplitude, but shortened TTP and prolonged $\mathrm{R}_{100}$. Inhibition of $\beta_{2}-\mathrm{AR}$ with ICI 118551 increased shortening amplitude in the Ovx +E group, prolonged TTP and shortened $\mathrm{R}_{100}$ in the $\mathrm{Ovx}+\mathrm{T}$ group, respectively, to the level of the Ovx group (Fig. 4).

\section{$E / T$ combination upregulated the expression of $\beta_{2}-A R$}

Ovx downregulated the expression of $\beta_{2}$-AR. Compared with $\mathrm{Ovx}, \mathrm{E}_{2}$ replacement alone, testosterone replacement alone, and combination supplementation all increased the expression of $\beta_{2}-\mathrm{AR}$. There was no significant difference in the expression of $\beta_{2}-\mathrm{AR}$ between $\mathrm{Ovx}+\mathrm{E}$ and $\mathrm{Ovx}$ $+\mathrm{T}$ groups. However, compared with $\mathrm{Ovx}+\mathrm{E}$ and Ovx $+\mathrm{T}$ groups, the expression of $\beta_{2}-\mathrm{AR}$ was higher in Ovx + E/T group (Fig. 5).

\section{Discussion}

To our knowledge, this study is the first to address that addition of physiological dose of testosterone to estrogen therapy enhances the cardioprotection of $\mathrm{E}_{2}$ in Ovx rat cardiomyocytes subjected to I/R. Our data showed that
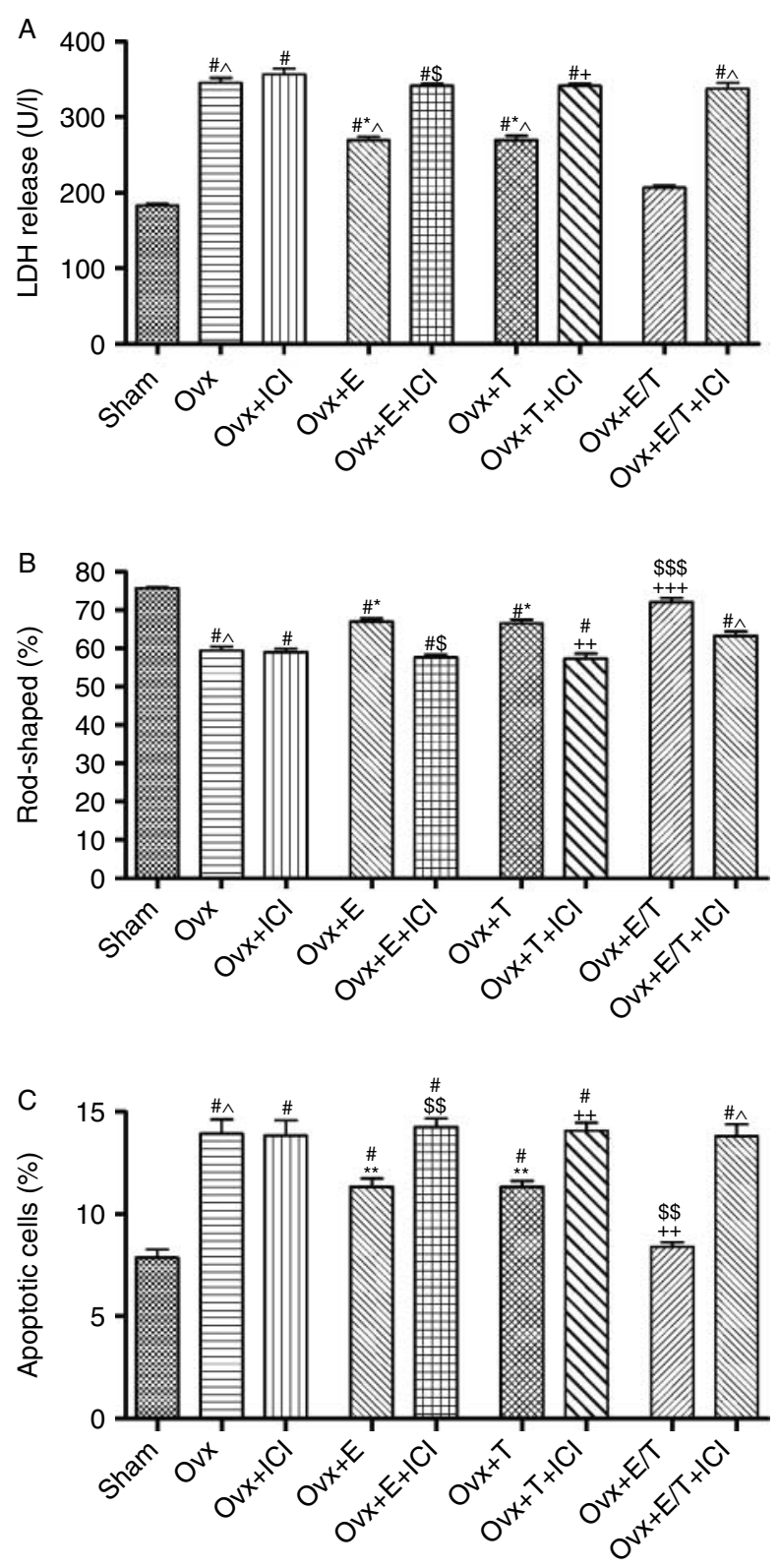

Figure $3 \mathrm{ICl} 118551$ (55 nM) abolished the effects of hormone replacement on injury and viability. (A) LDH release. (B) Percentage of rod-shaped cells. (C) Apoptotic cells (\%). Ventricular myocytes were subjected to I/R. Data shown are mean \pm S.E.M. $n=8$ hearts in each group. ${ }^{*} P<0.001$ vs Sham, ${ }^{*} P<0.001$ and ${ }^{* *} P<0.05$ vs Ovx, ${ }^{\$} P<0.001, \$ \$ P<0.01$, and ${ }^{\$ \$} P<0.05$ vs Ovx $+\mathrm{E}$, ${ }^{+} P<0 \cdot 001,{ }^{++} P<0 \cdot 01$, and ${ }^{++}+P<0 \cdot 05$ vs $\mathrm{Ovx}+\mathrm{T}$, and ${ }^{\wedge} P<0 \cdot 001$ vs Ovx $+\mathrm{E} / \mathrm{T}$. 

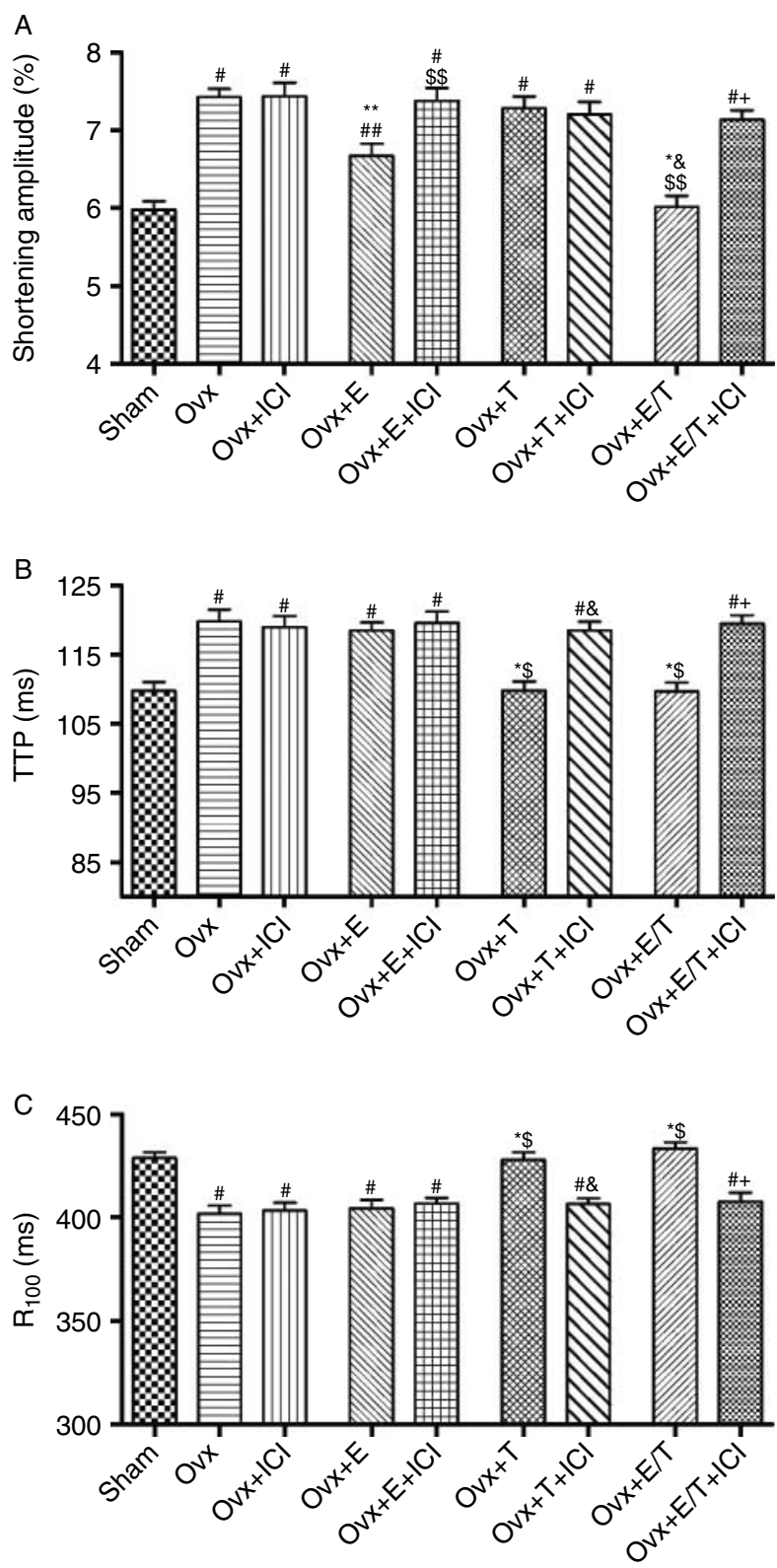

Figure $4 \mathrm{E} / \mathrm{T}$ combination improved contractile function and $\mathrm{ICl}$ $118551(55 \mathrm{nM})$ abolished the effects. (A) Shortening amplitude. (B) Time-to-peak (TTP) contraction (ms). (C) Time-to-100\% relaxation $\left(\mathrm{R}_{100} ; \mathrm{ms}\right)$. Ventricular myocytes were subjected to $\mathrm{I} / \mathrm{R}$. Data shown are mean \pm S.E.M. $n=8$ hearts in each group, $10-15$ cells were measured in each heart. ${ }^{\#} P<0.001$ and ${ }^{\# \#} P<0.05$ vs Sham, ${ }^{*} P<0.001$ and ${ }^{* *} P<0.01$ vs Ovx, ${ }^{\$} P<0.001$ and ${ }^{\$ \$} P<0.05$ vs $\mathrm{Ovx}+\mathrm{E},{ }^{\&} P<0.001$ vs $\mathrm{Ovx}+\mathrm{T}$, and ${ }^{+} P<0.001$ vs $\mathrm{Ovx}+\mathrm{E} / \mathrm{T}$.

$\mathrm{E}_{2}$ or testosterone replacement alone or combination supplementation reduced myocardial injury, increased viability, improved contractile function. Combination treatment appeared to be more effective than either $\mathrm{E}_{2}$ or testosterone replacement alone. We also found that the benefits of $\mathrm{E} / \mathrm{T}$ combination may be associated with $\beta_{2}-\mathrm{AR}$.
A number of clinical and experimental studies confirmed that estrogen has beneficial effects on the cardiovascular system, particularly in myocardial I/R injury, atherosclerosis, and arrhythmia (Booth \& Lucchesi 2008). Xin et al. (2002) found that estrogen plays a protective role in the hypertrophic response of the heart to $\mathrm{Ca}^{2+}$ dysregulation. Pretreatment of male rabbits with $\mathrm{E}_{2}$ before in vivo coronary artery ligation significantly reduced infarct size (Das et al. 2006). Physiological estrogen replacement reduced cardiomyocyte apoptosis after myocardial infarction in vivo in Ovx female mice (Patten et al. 2004). In this study, compared with the Ovx group, $\mathrm{E}_{2}$ replacement alone increased the percentage of rodshaped cells, reduced apoptotic cells (\%), improved contractile function, and decreased the LDH release. This is in agreement with the result of our previous studies in which $\mathrm{E}_{2}$ has been shown to play a cardioprotective role in female rat hearts subjected to I/R injury, and the effects of $E_{2}$ are associated with decreased cardiomyocyte contraction (Wu et al. 2008).

Studies demonstrated that estrogen may create an iatrogenic testosterone deficiency state (Casson et al. 1997, Shifren et al. 2007). In this study, 6 weeks after Ovx, the serum levels of $\mathrm{E}_{2}$ and total testosterone significantly fell; administration of $E_{2}$ alone to Ovx rats markedly increased serum $\mathrm{E}_{2}$ concentration and decreased total testosterone concentration. CVD is rare in women before menopause compared with men of the same age. However, women do not always fare better than men with respect to CVD (Luczak \& Leinwand 2009). The incidence of CVD in women increases after menopause; when comparing men and women over 65 years of age, this sexual dimorphism disappears and mortality is higher in postmenopausal women compared with age-matched men (Bhupathy et al. 2010). Postmenopausal women have approximately the same estrogen levels as do men, but approximately tenfold lower circulating testosterone levels than do men (Luczak \& Leinwand 2009). Testosterone circulates at concentrations that are an order of magnitude greater than those of $E_{2}$ in the blood of postmenopausal women (Simpson 2002). In addition, androgen receptors are expressed in female hearts (Nordmeyer et al. 2004, Lizotte et al. 2009). An implication of the above is that androgens have an important role in the higher risk of CVD in postmenopausal women. Increased cardiovascular events induced by estrogen replacement therapy may be associated with the decline of testosterone concentrations in postmenopausal women.

A large number of studies have demonstrated that testosterone replacement benefits cardiac recovery from $\mathrm{I} / \mathrm{R}$ injury in male rodent models. Callies et al. (2003) found that administration of testosterone reduced susceptibility to myocardial I/R injury, improved the recovery of cardiac contractile function. Tsang et al. (2008) demonstrated that testosterone reduced cardiac injury induced by $\mathrm{I} / \mathrm{R}$ and noradrenaline, in a model close to the in vivo situation in orchidectomized rats.

In this study, physiological dose of testosterone significantly reduced cardiac injury and apoptosis, increased survival, and 

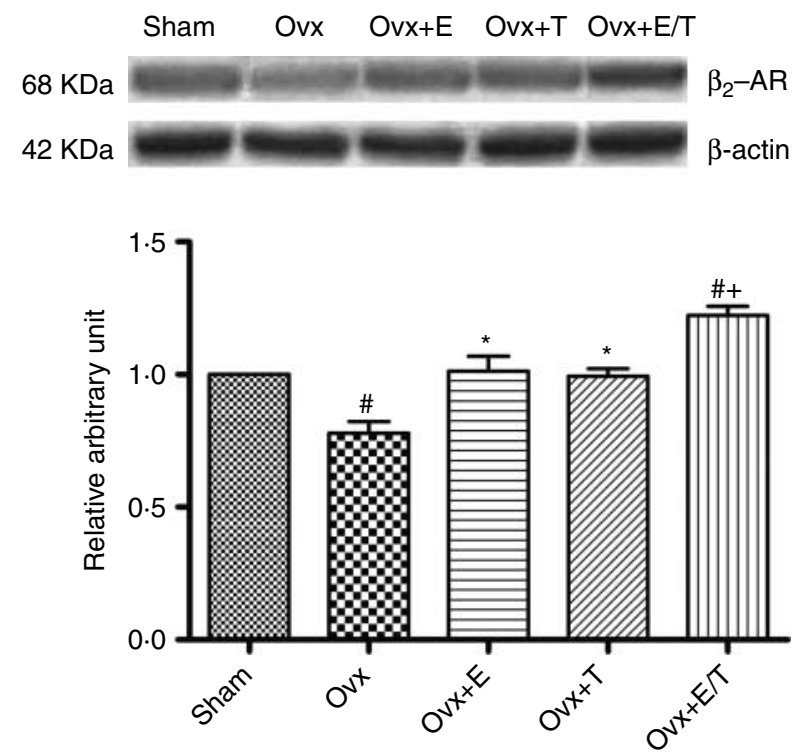

Figure $5 \mathrm{E} / \mathrm{T}$ combination upregulated the expression of $\beta_{2}-\mathrm{AR}$. The expression of $\beta_{2}$-adrenoceptors was evaluated by western blotting. The expression of $\beta$-actin was detected as an internal standard. The relative arbitrary unit for Sham group was assigned as 1 . Each value represents the mean \pm s.E.M. $n=6$ hearts in each group. ${ }^{\#} P<0 \cdot 05$ vs Sham, ${ }^{*} P<0 \cdot 05$ vs Ovx and Ovx $+\mathrm{E} / \mathrm{T}$, and ${ }^{+} P<0 \cdot 001$ vs Ovx.

to some extent, improved contractile function by shortening TTP and prolonging $\mathrm{R}_{100}$. Shortened TTP and prolonged $\mathrm{R}_{100}$ allow cardiomyocytes to rest for a longer time. Thus, the work time of myocytes was reduced and myocardial oxygen consumption was decreased and more energy was saved. These results are consistent with the observations that testosterone reduced apoptosis induced by hyperosmotic stress in the embryonic rat heart cell line H9c2 (Sánchez-Más et al. 2010) and reduced cardiac injury induced by $I / R$ and noradrenaline in orchidectomized rats (Tsang et al. 2008). Combined with our findings, results indicated that physiological dose of testosterone replacement has a direct protective effect on cardiomyocytes.

Taken together, although $\mathrm{E}_{2}$ plays a useful role in the cardiovascular system, it can cause the increase of cardiovascular events (Rossouw et al. 2002, Vickers et al. 2007). $\mathrm{E}_{2}$-only replacement results in testosterone deficiency, and testosterone replacement plays a protective role in cardiomyocytes. Therefore, addition of testosterone to $\mathrm{E}_{2}$ replacement therapy is reasonable in the prevention and treatment of CVD among postmenopausal women. In this study, addition of physiological dose of testosterone to $E_{2}$ therapy also had beneficial effects on myocardial survival and contractile function, and was significantly more effective than either $\mathrm{E}_{2}$ or testosterone supplementation alone. However, Cavasin et al. (2003) found that $\mathrm{E}_{2}$ and testosterone play different and opposing roles in the development of heart failure and long-term remodeling after myocardial infarction in mice; $E_{2}$ prevents maladaptive chronic remodeling and further deterioration of cardiac performance, whereas testosterone adversely affects myocardial healing, degrades cardiac dysfunction and remodeling, and exerts pronounced effects when $E_{2}$ levels are reduced. Nevertheless, it remains clear that the role of testosterone in myocardial injury requires further study.

In this study, in addition to the superior benefits on cardiac injury, survival and contractile function, $\mathrm{E} / \mathrm{T}$ combination supplementation restored body weight and heart weight/ body weight ratio compared to those of the Sham group. However, in Ovx $+\mathrm{T}$ group, body weight and heart weight/body weight ratio had no significant changes. Moreover, combination supplementation counteracted the fall of serum testosterone in Ovx $+\mathrm{E}$ group and the lower level of serum $\mathrm{E}_{2}$ in $\mathrm{Ovx}+\mathrm{T}$ group. Therefore, $\mathrm{E} / \mathrm{T}$ combination supplementation may be the best hormone therapy, compared with either $\mathrm{E}_{2}$ or testosterone replacement alone - it not only plays a protective role in cardiomyocytes, but may also be better at simulating the levels of premenopausal physiological state of hormone, causing few side effects.

The mechanisms through which combination supplementation would affect Ovx rat cardiomyocytes subjected to $\mathrm{I} / \mathrm{R}$ are still unclear, and this study, by its design, cannot directly answer this question. However, some tentative explanations can be advanced. Our previous studies indicated (Wu et al. 2008) that incubation of Ovx ventricular myocytes with $\mathrm{E}_{2}$ for $24 \mathrm{~h}$ significantly reduced the amplitude of myocellular shortening, reduced the protein expression of $\beta_{1}-\mathrm{AR}$ and increased the protein expression of $\beta_{2}-\mathrm{AR}$. The effect of $E_{2}$ was abolished by co-incubation with ICI 182780 , a high-affinity estrogen receptor antagonist. These data indicated that the action of $\mathrm{E}_{2}$ on the myocardial cells is mediated by estrogen receptors.

As to testosterone, most of the studies support the view that the cardiovascular effects of testosterone are androgen receptor-independent. Zhang et al. (2011) found that testosterone suppresses oxidative stress via androgen receptor-independent pathway in murine cardiomyocytes. In cultured cardiac myocytes, testosterone induced a rapid and nongenomic intracellular $\mathrm{Ca}^{2+}$ release through activation of a plasma membrane androgen receptor associated with the PTX-sensitive G protein-phospholipase C/IP3 signaling pathway (Vicencio et al. 2006). Bourghardt et al. (2010) found that testosterone atheroprotection was androgen receptor-dependent as well as androgen receptor-independent in male mice.

The conversion of testosterone to estrogen by aromatization may also be responsible for the protective action of testosterone, because of the presence of the aromatase enzyme within cardiac tissue. In this study, testosterone replacement alone increased the serum $\mathrm{E}_{2}$ level slightly, but there was no statistical significance, compared with Ovx group. So it is unlikely that $\mathrm{E}_{2}$ contributes significantly to the protective action of testosterone. 
Liou et al. (2010) indicated that chronic $\mathrm{E}_{2}$ treatment prevented bilateral ovariectomy-induced Fas receptordependent apoptotic pathways in rat models. In addition, studies found that estrogen reduced apoptosis of cardiomyocytes in vivo and in vitro by activating the phosphatidylinositol 3-kinase (PI3K)/protein kinase B (AKT) signaling pathway (Ren et al. 2003, Patten et al. 2004), which is a downstream pathway activated by $\beta_{2}$-AR stimulation (Xiao et al. 2006). Our previous study showed that $\mathrm{E}_{2}$ may protect heart via $\beta_{2}-\mathrm{AR}$ and subsequent signaling (Xu et al. 2010). Tsang et al. (2008) showed that $\beta_{2}$-AR was downregulated in rats without testosterone, indicating that testosterone may also interact with this receptor subtype. The cardiac protective effect of $\beta_{2}$-AR signaling is largely mediated by activating the cell survival pathway Gi-G $\beta \gamma-\mathrm{PI} 3 \mathrm{~K}-\mathrm{AKT}$, which not only counteracts apoptosis but also protects cardiomyocytes against other apoptotic stimuli (Zhu et al. 2005). It is likely that $\mathrm{E}_{2}$ and testosterone exert a cardiac protective effect through activating common signaling PI3K-AKT via $\beta_{2}$-AR. In this study, a selective $\beta_{2}$-AR antagonist ICI 118551 abrogated the protective effects of either $\mathrm{E}_{2}$ or testosterone alone or $\mathrm{E} / \mathrm{T}$ combination on cardiomyocytes subjected to I/R. Moreover, the expression of $\beta_{2}-A R$ was upregulated by $E_{2}$ or testosterone or E/T combination supplementation, especially by the latter. The results suggested that the cardioprotective effects of combination supplementation are associated with $\beta_{2}$-AR.

In conclusion, this study demonstrated that testosterone enhances $\mathrm{E}_{2}$ 's cardioprotection in Ovx rats, $\mathrm{E} / \mathrm{T}$ combination protects cardiomyocytes against $\mathrm{I} / \mathrm{R}$ injury, and the protective effects are at least partly mediated by $\beta_{2}-\mathrm{AR}$. Further studies are warranted to delineate the potential mechanisms and to explore the possible therapeutic application of $\mathrm{E} / \mathrm{T}$ combination in postmenopausal women with CVD.

\section{Declaration of interest}

The authors declare that there is no conflict of interest that could be perceived as prejudicing the impartiality of the research reported.

\section{Funding}

This work was supported by the research and innovation project of Xuzhou Medical College (XYCX201011) and Research Subjects of Xuzhou Medical College (2010KJ15).

\section{Acknowledgements}

We gratefully acknowledge the excellent technical assistance of Youjian Qi.

\section{References}

Bhupathy P, Haines CD \& Leinwand LA 2010 Influence of sex hormones and phytoestrogens on heart disease in men and women. Women's Health 6 77-95. (doi:10.2217/whe.09.80)
Booth EA \& Lucchesi BR 2008 Estrogen-mediated protection in myocardial ischemia-reperfusion injury. Cardiovascular Toxicology 3 101-113. (doi:10. 1007/s12012-008-9022-2)

Bourghardt J, Wilhelmson AS, Alexanderson C, De Gendt K, Verhoeven G, Krettek A, Ohlsson C \& Tivesten A 2010 Androgen receptor-dependent and independent atheroprotection by testosterone in male mice. Endocrinology 151 5428-5437. (doi:10.1210/en.2010-0663)

Callies F, Strömer H, Schwinger RH, Bölck B, Hu K, Frantz S, Leupold A, Beer S, Allolio B \& Bonz AW 2003 Administration of testosterone is associated with a reduced susceptibility to myocardial ischemia. Endocrinolgy 44 4478-4483. (doi:10.1210/en.2003-0058)

Casson PR, Elkind-Hirsch KE, Buster JE, Hornsby PJ, Carson SA \& Snabes MC 1997 Effect of postmenopausal estrogen replacement on circulating androgens. Obstetrics and Gynecology 90 995-998. (doi:10.1016/S00297844(97)00538-3)

Cavasin MA, Sankey SS, Yu AL, Menon S \& Yang XP 2003 Estrogen and testosterone have opposing effects on chronic cardiac remodeling and function in mice with myocardial infarction. American Journal of Physiology. Heart and Circulatory Physiology 284 H1560-H1569. (doi:10.1152/ajpheart. 01087.2002)

Das B \& Sarkar C 2006 Similarities between ischemic preconditioning and 17beta-estradiol mediated cardiomyocyte KATP channel activation leading to cardioprotective and antiarrhythmic effects during ischemia/reperfusion in the intact rabbit heart. Journal of Cardiovascular Pharmacology 47 277-286. (doi:10.1097/01.fjc.0000202563.54043.d6)

Das A, Smolenski A, Lohmann SM \& Kukreja RC 2006 Cyclic GMPdependent protein kinase I alpha attenuates necrosis and apoptosis following ischemia/reoxygenation in adult cardiomyocyte. Journal of Biological Chemistry 281 38644-38652. (doi:10.1074/jbc.M606142200)

Hao Y, Sun Y, Xu C, Jiang X, Sun H, Wu Q, Yan C \& Gu S 2009 Improvement of contractile function in isolated cardiomyocytes from ischemia-reperfusion rats by ginkgolide B pretreatment. Journal of Cardiovascular Pharmacology 54 3-9. (doi:10.1097/FJC. 0b013e3181a91410)

Iellamo F, Volterrani M, Caminiti G, Karam R, Massaro R, Fini M, Collins P \& Rosano GM 2010 Testosterone therapy in women with chronic heart failure. A pilot double-blind, randomized, placebo-controlled study. Journal of the American College of Cardiology 56 1310-1316. (doi:10.1016/j. jacc.2010.03.090)

Liou CM, Yang AL, Kuo CH, Tin H, Huang CY \& Lee SD 2010 Effects of 17beta-estradiol on cardiac apoptosis in ovariectomized rats. Cell Biochemistry and Function 28 521-528. (doi:10.1002/cbf.1687)

Lizotte E, Grandy SA, Tremblay A, Allen BG \& Fiset C 2009 Expression, distribution and regulation of sex steroid hormone receptors in mouse heart. Cellular Physiology and Biochemistry 23 75-86. (doi:10.1159/ 000204096)

Lucchinetti E, Jamnicki M, Fischer G \& Zaugg M 2008 Preconditioning by isoflurane retains its protection against ischemia-reperfusion injury in postinfarct remodeled rat hearts. Anesthesia and Analgesia 106 17-23. (doi:10.1213/01.ane.0000289527.70545.ed)

Luczak ED \& Leinwand LA 2009 Sex-based cardiac physiology. Annual Review of Physiology 71 1-18. (doi:10.1146/annurev.physiol.010908. 163156)

Montalcini T, Gorgone G, Gazzaruso C, Sesti G, Perticone F \& Pujia A 2007 Endogenous testosterone and endothelial function in postmenopausal women. Coronary Artery Disease 18 9-13. (doi:10.1097/01.mca. 0000236290.79306.d1)

Nordmeyer J, Eder S, Mahmoodzadeh S, Martus P, Fielitz J, Bass J, Bethke N, Zurbrügg HR, Pregla R, Hetzer R et al. 2004 Upregulation of myocardial estrogen receptors in human aortic stenosis. Circulation 110 3270-3275. (doi:10.1161/01.CIR.0000147610.41984.E8)

Patten RD, Pourati I, Aronovitz MJ, Baur J, Celestin F, Chen X, Michael A, Haq S, Nuedling S, Grohe C et al. 2004 17beta-estradiol reduces cardiomyocyte apoptosis in vivo via activation of phospho-inositide-3 kinase/Akt signaling. Circulation Research 95 692-699. (doi:10.1161/01. RES.0000144126.57786.89) 
Ren J, Hintz KK, Roughead ZK, Duan J, Colligan PB, Ren BH, Lee KJ \& Zeng H 2003 Impact of estrogen replacement on ventricular myocyte contractile function and protein kinase B/Akt activation. American Journal of Physiology. Heart and Circulatory Physiology 284 H1800-H1807.

Rossouw JE, Anderson GL, Prentice RL, LaCroix AZ, Kooperberg C, Stefanick ML, Jackson RD, Beresford SA, Howard BV, Johnson KC et al. 2002 Risks and benefits of estrogen plus progestin in healthy postmenopausal women: principal results from the Women's Heatlh Initiative randomized controlled trial. Journal of the American Medical Association 288 321-333. (doi:10.1001/jama.288.3.321)

Sánchez-Más J, Turpin MC, Lax A, Ruipérez JA, Valdés Chávarri M \& Pascual-Figal DA 2010 Differential actions of eplerenone and spironolactone on the protective effect of testosterone against cardiomyocyte apoptosis in vitro. Revista Española de Cardiología 63 779-787.

Shifren JL, Davis SR, Moreau M, Waldbaum A, Bouchard C, DeRogatis L, Derzko C, Bearnson P, Kakos N, O’Neill S et al. 2006 Testosterone patch for the treatment of hypoactive sexual desire disorder in naturally menopausal women: results from the INTIMATE NM1 Study. Menopause 13 770-779. (doi:10.1097/01.gme.0000227400.60816.52)

Shifren JL, Desindes S, Mcllwain M, Doros G \& Mazer NA 2007 A randomized, open-label, crossover study comparing the effects of oral versus transdermal estrogen therapy on serum androgens, thyroid hormones, and adrenal hormones in naturally menopausal women. Menopause 14 985-994. (doi:10.1097/gme.0b013e318032c505)

Sievers C, Klotsche J, Pieper L, Schneider HJ, Marz W, Wittchen HU, Stalla GK \& Mantzoros C 2010 Low testosterone levels predict all-cause mortality and cardiovascular events in women: a prospective cohort study in German primary care patients. European Journal of Endocrinology 163 699-708. (doi:10.1530/EJE-10-0307)

Simpson ER 2002 Aromatization of androgens in women: current concepts and findings. Fertility and Sterility 77 S6-S10. (doi:10.1016/S0015-0282 (02)02984-9)

Sun H, Zhou F, Wang Y, Zhang Y, Chang AM \& Chen Q 2006 Effects of $\beta$-adrenoceptors overexpression on cell survival are mediated by $\mathrm{Bax} / \mathrm{Bcl}-2$ pathway in rat cardiac myocytes. Pharmacology 78 98-104. (doi:10.1159/ 000095785)

Tsang S, Wu S, Liu J \& Wong TM 2008 Testosterone protects rat hearts against ischemic insults by enhancing the effects of $\alpha 1$-adrenoceptor stimulation. British Journal of Pharmacology 153 693-709. (doi:10.1038/sj.bjp.0707624)

Tsang S, Wong SS, Wu S, Kravtsov GM \& Wong TM 2009 Testosteroneaugmented contractile responses to $\alpha_{1}$ - and $\beta_{1}$-adrenoceptor stimulation are associated with increased activities of RyR, SERCA, and NCX in the heart. American Journal of Physiology. Cell Physiology 296 C766-C782. (doi:10.1152/ajpcell.00193.2008)
Vicencio JM, Ibarra C, Estrada M, Chiong M, Soto D, Parra V, Diaz-Araya G, Jaimovich E \& Lavandero S 2006 Testosterone induces an intracellular calcium increase by a nongenomic mechanism in cultured rat cardiac myocytes. Endocrinology 147 1386-1395. (doi:10.1210/en.2005-1139)

Vickers MR, Maclennan AH, Lawton B, Ford D, Martin J, Meredith SK, DeStavola BL, Rose S, Dowell A, Wilkes HC et al. 2007 Main morbidities recorded in the women's international study of long duration oestrogen after menopause (WISDOM): a randomised controlled trial of hormone replacement therapy in postmenopausal women. BMJ 335 239-244. (doi:10.1136/bmj.39266.425069.AD)

Wu Q, Zhao Z, Sun H, Hao YL, Yan CD \& Gu SL 2008 Estrogen changed cardiomyocyte contraction and beta-adrenoceptor expression in rat hearts subjected to ischemia-reperfusion. Experimental Physiology 93 1034-1043. (doi:10.1113/expphysiol.2007.041939)

Xiao RP, Zhu W, Zheng M, Cao C, Zhang Y, Lakatta EG \& Han Q 2006 Subtype-specific alpha1- and beta-adrenoceptor signaling in the heart. Trends in Pharmacological Sciences 6 330-337. (doi:10.1016/j.tips.2006. 04.009)

Xin HB, Senbonmatsu T, Cheng DS, Wang YX, Copello JA, Ji GJ, Collier ML, Deng KY, Jeyakumar LH, Magnuson MA et al. 2002 Oestrogen protects FKBP12.6 null mice from cardiac hypertrophy. Nature 6878 334-338. (doi:10.1038/416334a)

Xu X, De Pergola G \& Bjorntorp P 1991 Testosterone increases lipolysis and the number $\beta$-adrenoreceptors in male rat adipocytes. Endocrinology 128 379-381. (doi:10.1210/endo-128-1-379)

Xu C, Liu A, Sun H, Sun Y, Wang G, Gao L, Hao Y \& Yan C 2010 $\beta_{2}$-Adrenoceptor confers cardioprotection against hypoxia in isolated ventricular myocytes and the effects depend on estrogenic environment. Journal of Receptors and Signal Transduction Research 30 255-261. (doi:10. 3109/10799893.2010.488242)

Zhang L, Wu S, Ruan Y, Hong L, Xing X \& Lai W 2011 Testosterone suppresses oxidative stress via androgen receptor-independent pathway in murine cardiomyocytes. Molecular Medicine Reports 4 1183-1188.

Zhu W, Zeng X, Zheng M \& Xiao RP 2005 The enigma of $\beta_{2}$-adrenergic receptor Gi signaling in the heart: the good, the bad, and the ugly. Circulation Research 97 507-509. (doi:10.1161/01.RES.0000184615. 56822.bd)

Received in final form 17 September 2011 Accepted 30 September 2011 Made available online as an Accepted Preprint 30 September 2011 